\title{
Methodology for the Design of an Aerodynamic Package for a Formula SAE Vehicle.
}

\author{
Author, co-author (Chris Craig, Martin Passmore) \\ Affiliation (Loughborough University)
}

Copyright $(2014$ SAE International

\begin{abstract}
Recent changes to the rules regarding aerodynamics within Formula SAE, combined with faster circuits at the European FSAE events, have made the implementation of aerodynamic devices, to add down-force, a more relevant topic. As with any race series it is essential that a detailed analysis is completed to establish the costs and benefits of including an aerodynamic package on the vehicle. The aim of the work reported here was to create a methodology that would fully evaluate all aspects of the package and conclude with an estimate of the likely gain in points at a typical FSAE event. The paper limits the analysis to a front and rear wing combination, but the approach taken can be applied to more complex aerodynamic packages
\end{abstract}

An initial wind tunnel investigation of the potential flow interactions between the driver's helmet and rear wing using a multi-hole pressure probe is reported and the data used in a two-dimensional CFD calculation to provide an accurate prediction of the likely down-force from the wing package. The chosen configurations are tested in a comprehensive wind tunnel program and a map of potential setups generated. The potential aerodynamic configurations are assessed in both quasi-static and dynamic handling analysis to demonstrate the effects of aerodynamic lift, lift distribution, aerodynamic drag, and the effect of additional weight, weight distribution and height of the center of gravity. The paper includes a description of the wind tunnel model and scaling considerations and a description of the handling model and the lap simulation methods.

The results shows that a simple front and rear wing combination, providing relative low down-force $(1000 \mathrm{~N}$ at $110 \mathrm{kph}$ on a vehicle of $280 \mathrm{~kg}$, including driver), gives an improvement in performance equating to a gain of approximately 40 points during the event. The largest improvements are seen during the autocross and endurance events. This gain is considered sufficient to justify the inclusion of the package on the vehicle.

\section{Introduction}

Aerodynamics within motorsport is an ever evolving area. Aerodynamic devices to generate down-force as a route to faster cornering speeds have been employed in mainstream racing series since the 1960's, for example in Can-Am and Page 1 of 10
Formula 1 . The success of the approach has subsequently filtered down into other series where competitors and designers have exploited the considerable advantages that they offer in improving lap times.

In practice, with the evolution of the sport, most race series have introduced restrictions on the use of aerodynamic devices, or have tightly controlled their application via the series regulations. For example this may include restrictions regarding position, shape and size of allowable devices and the complete banning of others.

Formula SAE (FSAE) is an exception to this as the rules are essentially free in terms of positioning and design of aerodynamic devices. This freedom is possible because in FSAE the average speed of the vehicle has typically been quite low making the exploitation of aerodynamics more difficult and the potential gains relatively small. In recent years, however, a change in style of FSAE circuits to more gradual changes of curvature, instead of the sharp changes of direction associated with previous competitions has made higher speeds possible and has resulted in an increase in average speed of around $10 \mathrm{~km} / \mathrm{h}$.

This change in track style has led to an increase in numbers of vehicles utilizing aerodynamic aids (Figure 1). In the 2012 UK event these ranged from small single element wings and flat floors, to large quadruple element wings and fully shaped under bodies. In 2012 at Formula Student Germany, 17 cars had an aerodynamic device, either wings or shaped underfloors. Ten of these vehicles finished in the top 20 and the top five cars all employed such devices.

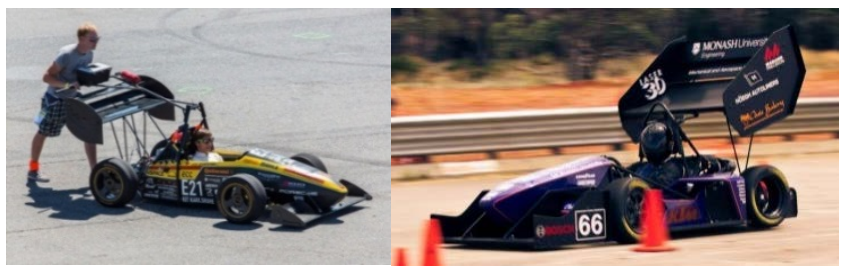

Figure 1. Karlsruhe Institute of Technology and Melbourne Monash 2012 FSAE Vehicles.

There are a number of publications exploring FSAE performance, including some that refer to how an aerodynamic package improves performance (Monash [1][2]), how to use 
CFD to design a large wing (Chalmers[3]) and both sources cover the broad performance benefits. They do not however provide any in depth analysis or description of specific techniques, methodologies and geometries, or a detailed evaluation of the benefits of implementing particular devices.

This paper addresses this gap and provides a starting point for any team wishing to implement an aerodynamic package on a FSAE vehicle. The aim is to describe a methodology that fully evaluates all aspects of the aerodynamic package. This includes the design of the wing sections, experimental and computational methods, evaluation of the dynamic performance and finally an estimate of the likely gain in points at a typical FSAE event. The paper limits the analysis to a front and rear wing combination, but the approach taken can be applied to any combination of aerodynamic devices or an integrated complex aerodynamic package.

\section{Experimental methodology}

The design methodology employed here combines experimental work carried out in the Loughborough University model scale Wind Tunnel with a number of simulation techniques. CFD modeling was conducted using a commercial code on quad core processors with 16GB RAM, and all dynamic simulation was completed using a purpose written program in MATLAB and Simulink running on the same computer hardware.

It is recognized that many teams may not have access to comparable experimental facilities but by validating the computational methodology used here the intention is that any team can use the simulation methods to implement a basic aerodynamic package into their design.

\section{Wind Tunnel}

The Loughborough Large Wind Tunnel (figure 2) is a novel open circuit horseshoe design allowing for a relative large working section of $1.92 \mathrm{~m} \times 1.32 \mathrm{~m}$ (width $\mathrm{x}$ height) within the constraints of the total floor space. Normal working section velocity is $40 \mathrm{~m} / \mathrm{s}$ with a turbulence intensity of $0.2 \%$ and spatial uniformity is $+/-0.4 \%$. Full details can be found in Johl [4]. Force and moment measurements are made via a 6 component under-floor balance with an integrated yaw drive. When testing a $1 / 4$ scale automotive model; a repeatability of $+/$ 2 drag counts is typical when fully removing and reinstalling the model. All force and moment data reported in this paper is averaged over a 30 second sampling period.

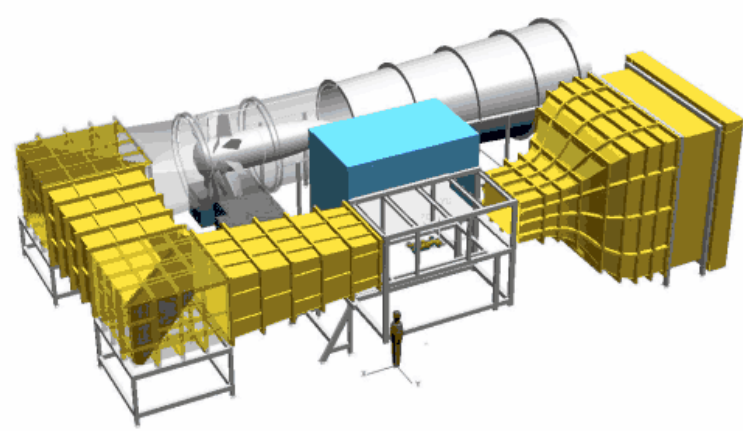

Figure 2. CAD Model of Loughborough Large Wind Tunnel.

The tunnel uses a fixed floor that gives a boundary layer thickness $\left(\delta^{99}\right)$ of approximately $50 \mathrm{~mm}$ at the front of the model location in normal operation. As this model requires a relatively low ground clearance, particularly the front wing, a reduction in boundary layer thickness was essential. A common approach is to introduce a separate suspended ground plane. While this is an effective method for reducing boundary layer thickness it adds complexity to the model mounting and measurement method when an underfloor balance is employed, as in this case. It was therefore decided to install a $25 \mathrm{~mm}$ high, vshaped boundary layer trip upstream of the model and measure the reduction in the boundary layer thickness. The arrangement is shown in figure 3 .

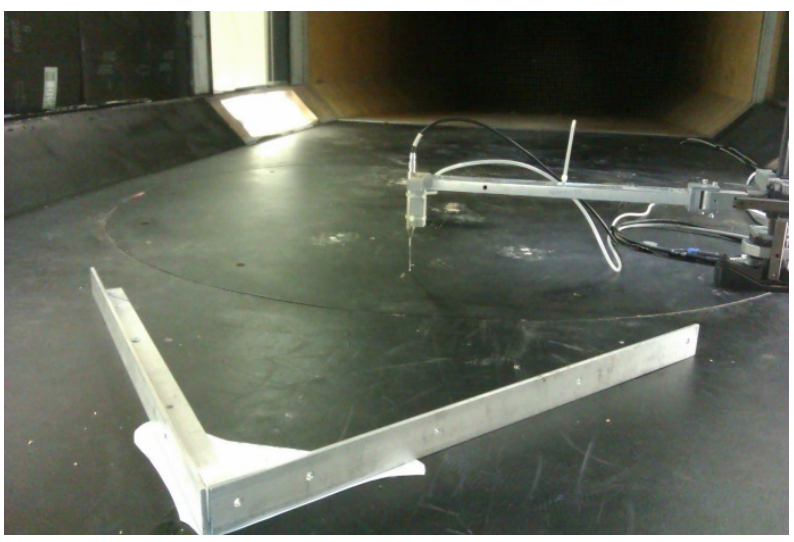

Figure 3. Boundary layer trip installed in the wind tunnel. Also showing instrumentation for measuring the boundary layer thickness.

By conducting a sweep of the internal angle for the trip and its location upstream, the optimum configuration of an 80 deg angle located $1000 \mathrm{~mm}$ upstream of the model front impingment was identified. This results in a boundary layer thickness $\left(\delta^{99}\right)$ of approximately $14 \mathrm{~mm}$. The comparison of with and without the trip is illustrated in Figure 4 and includes a measurement on the model centerline and displaced $100 \mathrm{~mm}$ laterally. The boundary layer measurements were taken using a 4-hole TSI Cobra probe providing flow velocity and an estimate of turbulence intensity. 


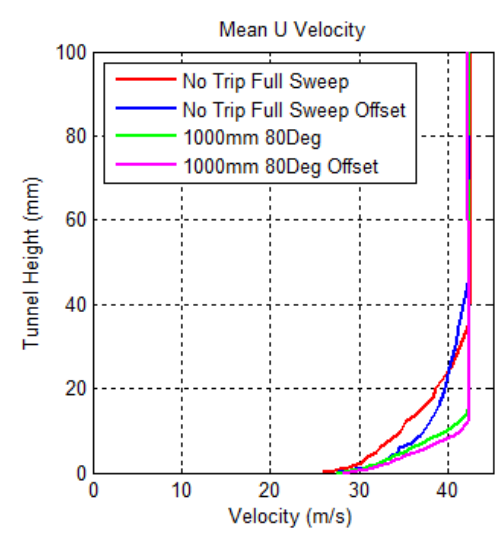

Figure 4. Effects of Boundary Trip Installation on U-Velocity on the tunnel centerline and $100 \mathrm{~mm}$ laterally from the centerline.

\section{Model Design}

The model is based on the 2012/2013 Loughborough University Formula Student Vehicle. To reduce Reynolds sensitivity, small features such as the engine detail, engine intake and roll hoops have been removed. Newnham [5] has shown that drag of a simplified model is affected by model leading radii, leading to post or pre critical flow. On the real FSAE vehicle the nose radius must be a minimum of $75 \mathrm{~mm}$. Based on an average speed of $25 \mathrm{~m} / \mathrm{s}$ and using the minimum edge radius, a real car Reynolds number of $1.20 \times 10^{5}$ based on edge radius is obtained; Newnham's work shows this value to be located in the region between trans and post critical. Therefore all nose radii on the model must have a Reynolds number greater than $1.20 \times 10^{5}$ to ensure similar flow behavior, resulting in a minimum model scale radius of $45 \mathrm{~mm}$.

Other components have been omitted for experimental simplicity; the side-pods have been removed as the fixed ground plane makes wheel flows inaccurate which are the primary contributors to flow condition in this region (they also will have little effect on the flow conditions that are in the wing positions). These may be added in future if required. A 3D CAD image of the model is shown in figure 5.

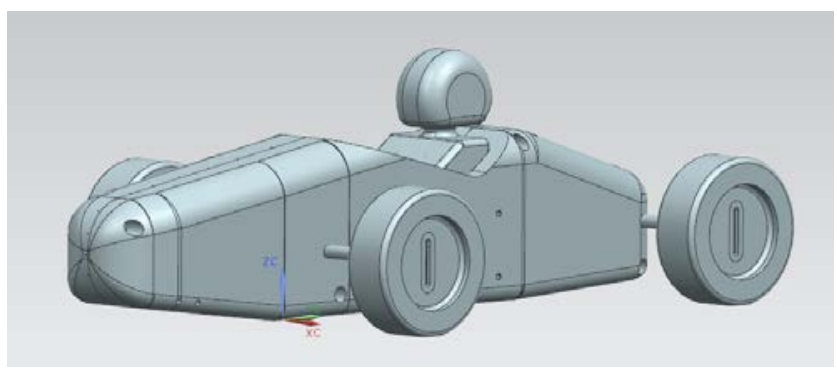

Figure 5. 5/18 ${ }^{\text {th }}$ Scale Windtunnel Model.

A model scale of $5 / 18^{\text {th }}$ was chosen to allow for a wide range of aerodynamic components to be tested in future work without overloading the force balance.
Ride height adjustments are made at the wheel hubs, with both positive (3 fixed adjustments) and sliding adjustments possible. An hatch located in front of the driver gives access to pressure tappings and pressure scanners although results from these are not included in this paper. The driver shoulders and helmet are removable and can therefore be replaced if required.

The model body is CNC manufactured in two halves from medium density machinable polyurethane model board. It is then held together with dowel pins and $4 \mathrm{M} 6$ bolts. Axles are produced from mild steel and press fit into one side of the model body. The wheels are made from high density model board with acrylic inserts for the ride height adjustment.

During initial testing a Reynolds sweep confirmed the model to be insensitive to Reynolds numbers above $\mathrm{Re}=6 \times 10^{5}$ (based on wheelbase) corresponding to a full scale vehicle speed of $5 \mathrm{~m} / \mathrm{s}$, demonstrating the applicability of the results to full scale. All subsequent wind tunnel testing was conducted at a Reynolds number of $1.0 \times 10^{6}$. The initial testing was also used to verify that the setup procedure produced repeatable results.

\section{Performance analysis}

Before designing the aerodynamic package a lap simulation tool was developed to determine the value of any aerodynamic down-force and compared with changes in vehicle mass and weight distribution. Two approaches are taken. A lap simulation is used to broadly quantify the gains and a dynamic model is used to assess the effect on the handling limits.

Lap simulation tools are now widely used across motorsport as a method of predicting the vehicle performance and making informed setup changes.

The Milliken Moment Method [6] allows a calculation of vehicle stability in a quasi-static scenario. Tire slip ratios and steered angles are input into the model and the tire forces balanced by modifying the body slip angle. The balancing is calculated using a non-linear least squares optimization, implemented in Matlab, with the weight transfer allowed to settle until differences between two iterations are less than $0.01 \mathrm{~N}$. This produces a hemispherical plot of lateral and longitudinal accelerations, with the limits of this hemisphere providing the limit of the vehicle.

These performance envelopes are constructed in $5 \mathrm{~m} / \mathrm{s}$ increments; interpolation between the $5 \mathrm{~m} / \mathrm{s}$ intervals then creates a full vehicle performance envelope. Example plots at 10 and $20 \mathrm{~m} / \mathrm{s}$ are illustrated in figure 6 . The performance envelope is then used in conjunction with the racing line to simulate a lap. 

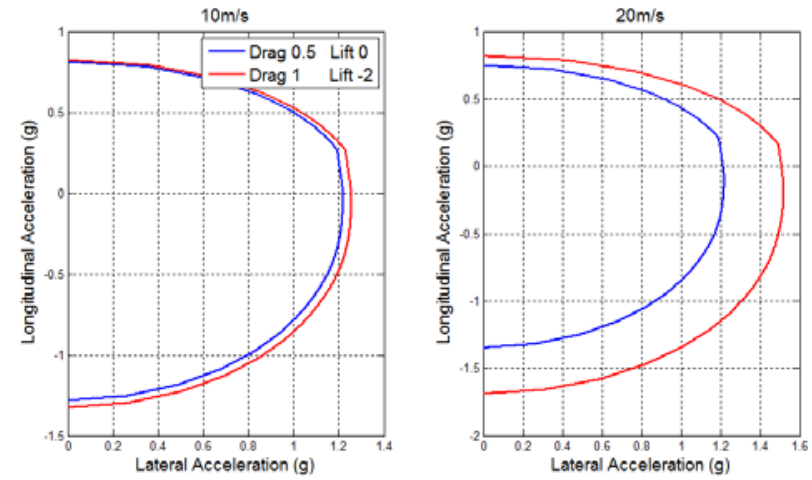

Figure 6. Performance Envelope with Two Aerodynamic Configurations.

Because the track varies at each FSAE event a bespoke test circuit was devised to capture all of the important features of a typical circuit. This is illustrated in figure 7.

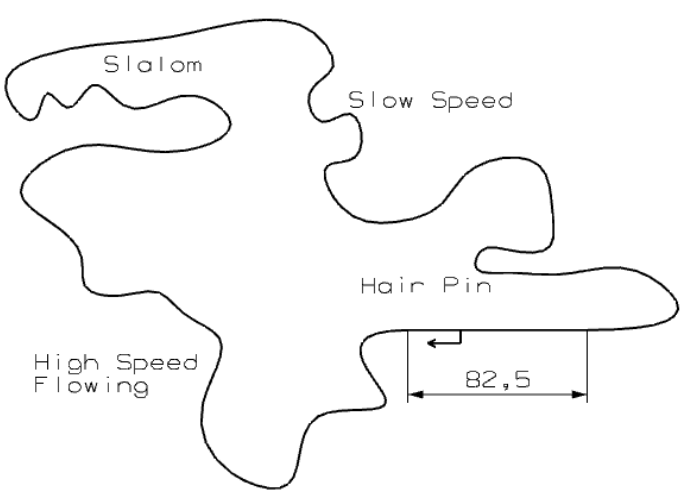

Figure 7. Bespoke Design FSAE Track, Dimension in meters.

The lap simulation was applied, using the methodology shown in figure 8, to the endurance and autocross events to determine the sensitivity of the vehicle to a number of design parameters. This was assessed in terms of the potential improvement in the points awarded at the event. A summary of the points system is given in appendix one.

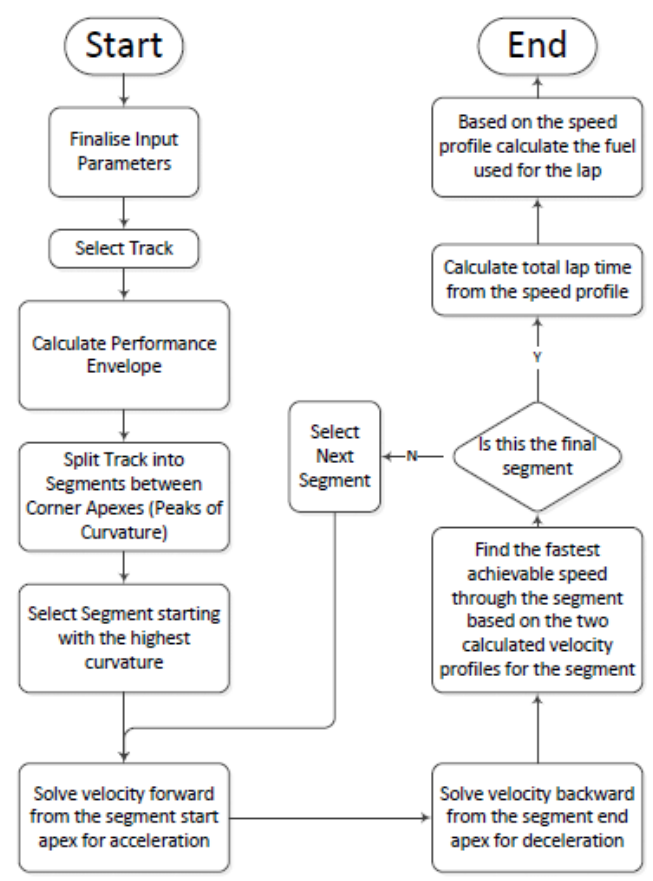

Figure 8. Lap Simulation Methodology.

Table 1 shows the sensitivities to Mass and CoG height for the Loughborough FSAE vehicle. It can be seen that although the mass and CoG do need to be considered, they do not have a large impact on the maximum performance of the vehicle.

Table 1. Mass and CoG Height Sensitivity.

\begin{tabular}{|l|l|l|}
\hline Event & Mass & CoG Height \\
& Points Sensitivity & Points Sensitivity \\
\hline Autocross & -0.11 Points per $\mathrm{kg}$ & -0.0118 Points per $\mathrm{mm}$ \\
\hline Endurance & -0.19 Points per $\mathrm{kg}$ & -0.0315 Points per $\mathrm{mm}$ \\
\hline Efficiency & -0.25 Points per $\mathrm{kg}$ & -0.051 Points per $\mathrm{mm}$ \\
\hline
\end{tabular}

Table 2 shows the impact of drag and total down-force on the points awarded. As expected an increase in drag causes a loss of points in all events but increasing down-force offers significant improvements in both the endurance and autocross events accompanied by a small penalty in efficiency (fuel consumption). This small reduction in points in efficiency is due to the greater grip capacity during traction and higher cornering speeds. The value of using a lap simulation becomes particularly clear from this data because typically increases in down-force are accompanied by increases in drag and the net gain is the important criteria for judging the package. It also illustrates the need to ensure that any aerodynamic package is aerodynamically efficient, i.e. that it has a good lift to drag ratio. 
Table 2. Drag and Downforce Sensitivity.

\begin{tabular}{|l|l|l|}
\hline Event & $\begin{array}{l}\text { Drag } \\
\text { Points Sensitivity }\end{array}$ & Downforce \\
& Points Sensitivity \\
\hline Autocross & $\begin{array}{l}-2.27 \text { Points per } 1000 \\
\text { counts }\end{array}$ & $\begin{array}{l}6.05 \text { Points per } 1000 \\
\text { counts }\end{array}$ \\
\hline Endurance & $\begin{array}{l}-3.99 \text { Points per } 1000 \\
\text { counts }\end{array}$ & $\begin{array}{l}10.62 \text { Points per } 1000 \\
\text { counts }\end{array}$ \\
\hline Efficiency & $\begin{array}{l}-6.65 \text { Points per } 1000 \\
\text { counts }\end{array}$ & $\begin{array}{l}-0.43 \text { Points per } 1000 \\
\text { counts }\end{array}$ \\
\hline
\end{tabular}

The handling effects of an aerodynamic package, including the effects of aerodynamic yaw moment, were evaluated using a six degree of freedom dynamic handling model. The model has an input interface of steer angle, throttle position and brake force, along with a braking control and speed control module, and allows a variety of set maneuvers to be completed. The model allows more sophisticated aerodynamic packages to be analyzed than outlined here, for example the trade-off between total lift and yaw moment associated with end plate geometry. In this paper its use is limited to analysis of the lift distribution.

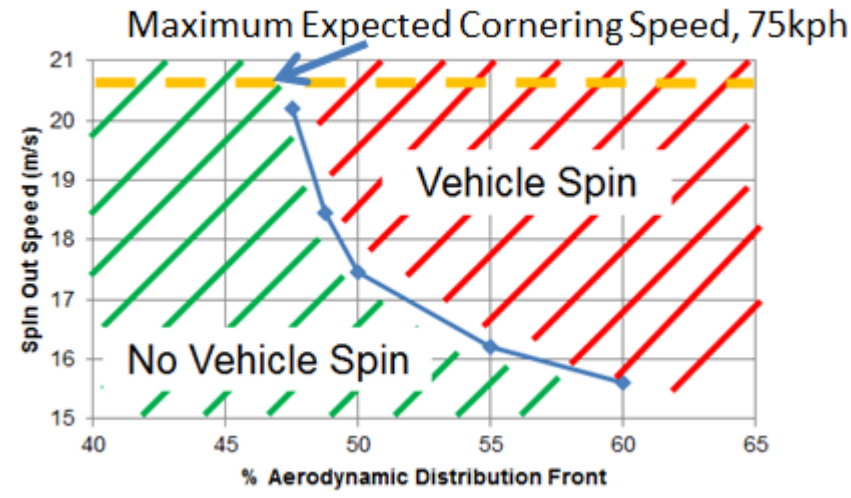

Figure 9. Vehicle Spin Out Speed (Stability) with Varied Aerodynamic Distribution.

Figure 9 shows the impact of lift distribution, indicating that for aerodynamic configurations where less than approximately $47 \%$ of the down force is acting on the front axle the speed at which the vehicle would theoretically spin is greatly increased. This is because the down-force at the rear of the vehicle makes the lateral force at the rear of the vehicle greater than the front lateral force. This gives a progressively more understeering vehicle.

The lap simulation and dynamic model were used to explore the design space and a set of targets for a front and rear wing combination was derived that were compatible with the use of a simple front and rear wing setup. The targets are summarized in table 3 . A specific target for front and rear lift is not included because it was necessary to allow flexibility later to adjust the aerodynamic balance depending on the final vehicle weight distribution. This adjustability was provided for by including a flap on both front and rear wings to provide the necessary adjustment.

Page 5 of 10
Table 3. Design Targets. For the full scale vehicle.

\begin{tabular}{|l|l|l|l|l|}
\hline $\begin{array}{l}\text { Lift } \\
\text { Coefficient }\end{array}$ & $\begin{array}{l}\text { Drag } \\
\text { Coefficient }\end{array}$ & $\begin{array}{l}\text { Front Wing } \\
\text { Mass }(\mathrm{kg})\end{array}$ & $\begin{array}{l}\text { Rear Wing } \\
\text { Mass }(\mathrm{kg})\end{array}$ & $\begin{array}{l}\text { Points } \\
\text { Gain }\end{array}$ \\
\hline-1.8 & 0.6 & 2.5 & 4 & 15 \\
\hline
\end{tabular}

\section{Baseline model testing}

Prior to designing a front and rear wing package the baseline model was investigated. This includes a map of the drag, lift and pitching moment for a range of front and rear ride heights and measurements of the flow-field directly behind the drivers head. This latter measurement was required to provide input data for the 2D CFD of the rear wing.

The force and moment data for zero yaw is summarized in Figure 10. The drag is relatively insensitive to changes in ride height but there is a small reduction in drag with negative pitch (maximum of 5 counts). The lift coefficient is generally insensitive to rear ride height changes but there is about a 20 count increase in lift as the front ride height increases from 10 to $30 \mathrm{~mm}$.

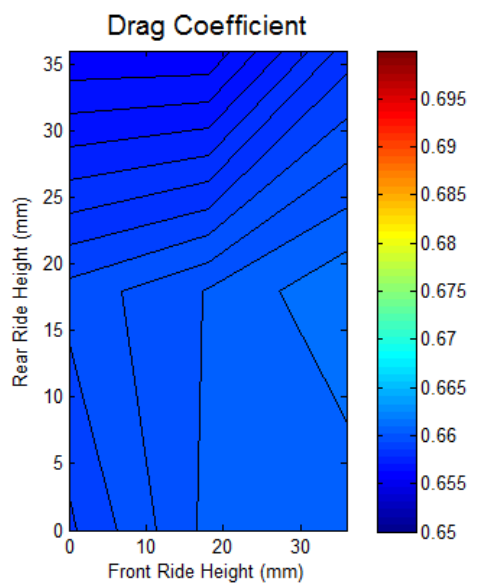

a)

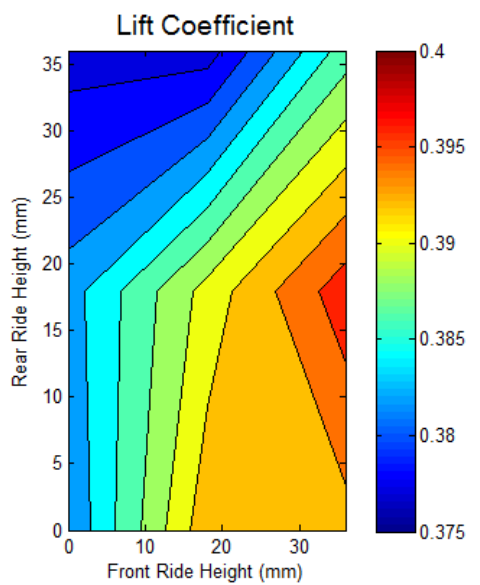

b) 


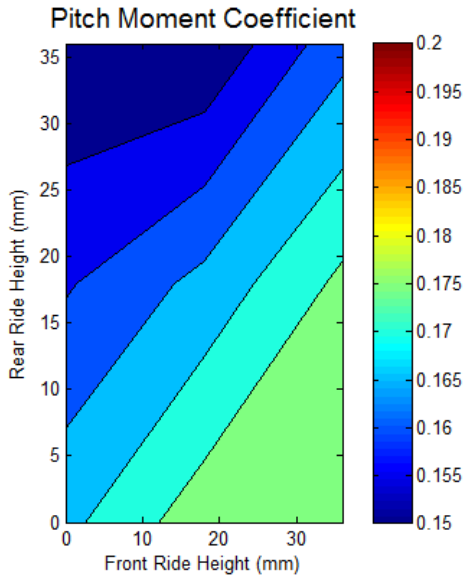

c)

Figure 10. a) Drag, b) Lift and c) Pitch Moment Coefficient Ride Height Maps.

Figure 5 shows the drivers helmet to be in an exposed position within the airflow and likely to dominate the flow onto the rear wing. To quantify this and provide input data for the rear wing design, the flow was mapped using a TSI Cobra Probe mounted to an automatic traverse, as shown in Figure 11.

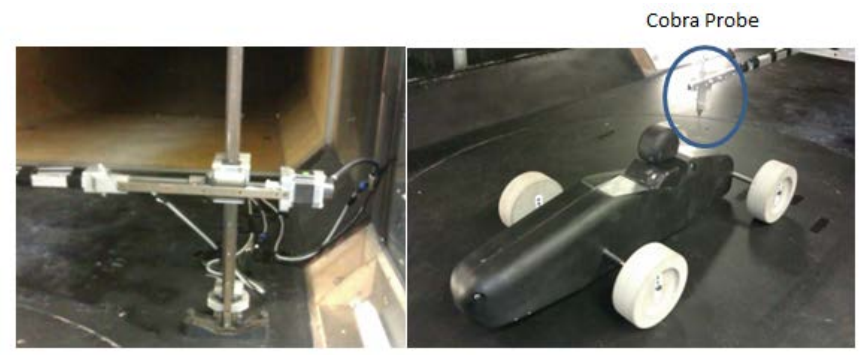

Figure 11. Flow Measurement Setup.

A sample of the velocity field obtained is shown in figure 12, areas of flow that are potentially important to the performance of the rear wing are directly behind the helmet and just to the side of the helmet where there is highly turbulent out of plane motion emanating from the radii on the side of the helmet

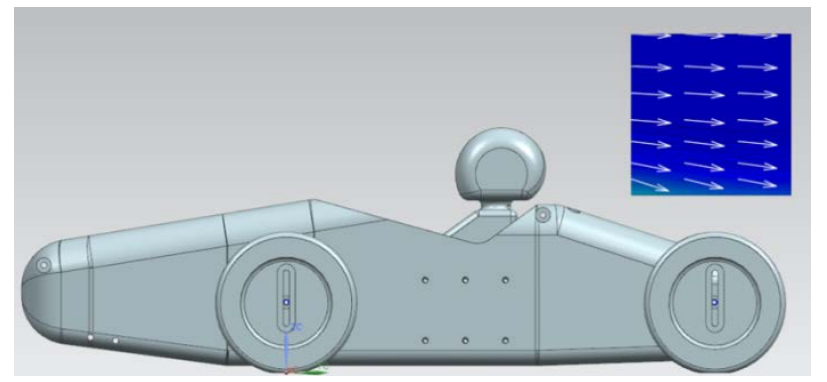

Figure 12. Flow Direction and Turbulence Intensity behind the helmet. Page 6 of 10

\section{Wing design}

With the design of a shaped underbody ruled out as this could not be optimized in a fixed ground plane wind tunnel, front and rear wings using a NACA 9418 profile for both a main element and a flap are proposed to achieve the down-force target specified previously (Table 3 ). The front and rear wings are the same apart from the flap on the front wing, where the central portion is removed close to the body. The inclusion of the flap allows for refinement of the aerodynamic balance of the vehicle through flap angle changes.

Table 4. Wing Profiles for the full scale vehicle.

\begin{tabular}{|l|l|l|l|l|}
\hline & Profile & Chord & $\begin{array}{l}\text { Max } \\
\text { Thickness }\end{array}$ & Camber \\
\hline Mainplane & $\begin{array}{l}\text { NACA } \\
9418\end{array}$ & $0.3 \mathrm{~m}$ & $\begin{array}{l}18 \% \text { at } 40 \% \\
\text { of chord }\end{array}$ & $9 \%$ \\
\hline Flap & $\begin{array}{l}\text { NACA } \\
9418\end{array}$ & $\begin{array}{l}0.12 \mathrm{~m}(40 \% \\
\text { Mainplane })\end{array}$ & $\begin{array}{l}18 \% \text { at } 40 \% \\
\text { of chord }\end{array}$ & $9 \%$ \\
\hline
\end{tabular}

For the experimental work both the front and rear wings are of a modular construction. The main plane consists of high density model board wing sections slotted onto 2 steel spars, with the flaps consisting of $2 \mathrm{~mm}$ thick laser cut steel profiles, once again assembled onto 2 steel spars. The end plates consist of $3 \mathrm{~mm}$ thick laser cut aluminum, with holes to locate the spars and set flap angles. This method of construction means that different wing spans can be tested at a later date.

\section{Two-Dimensional CFD Analysis}

To allow a large number of configurations of the wing to be evaluated 2D CFD was performed using a commercial CFD package. For the rear wing predictions the measured inlet velocity, direction $\left( \pm 10^{\circ}\right.$ onset incidence) and turbulence intensity (varied from $0.1 \%$ to $10 \%$ ) at various lateral locations behind the drivers head are used to perform a series of 2D CFD predictions that are interpolated to predict the overall wing performance with regard to lift and drag. This was considered preferable to using 3D CFD because of the large increase in computational time this would incur, but is an area worthy of further work. For the front wing, freestream conditions have been assumed although it is clear that this will greatly underestimate the likely down-force.

As recommended by Doddegowda [7], a k-epsilon turbulence model was utilized, with the CFD completed at a nominal freestream velocity of $20 \mathrm{~m} / \mathrm{s}$ with the wings at the chord length they would appear on the vehicle (giving a Reynolds number based on chord length of $4.69 \times 10^{6}$ ). In comparison, the wind tunnel model versions of the wing have a Reynolds number of $2.6 \times 10^{6}$; the Reynolds sensitivity was checked during the wind tunnel tests. A typical mesh is shown in Figure 13. 


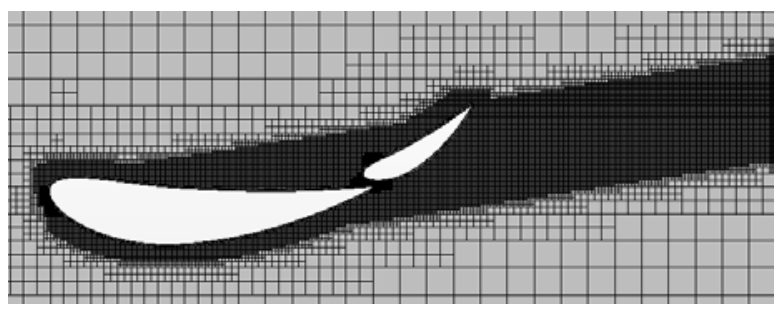

Figure 13. Mesh around profiles showing Wake Refinement.

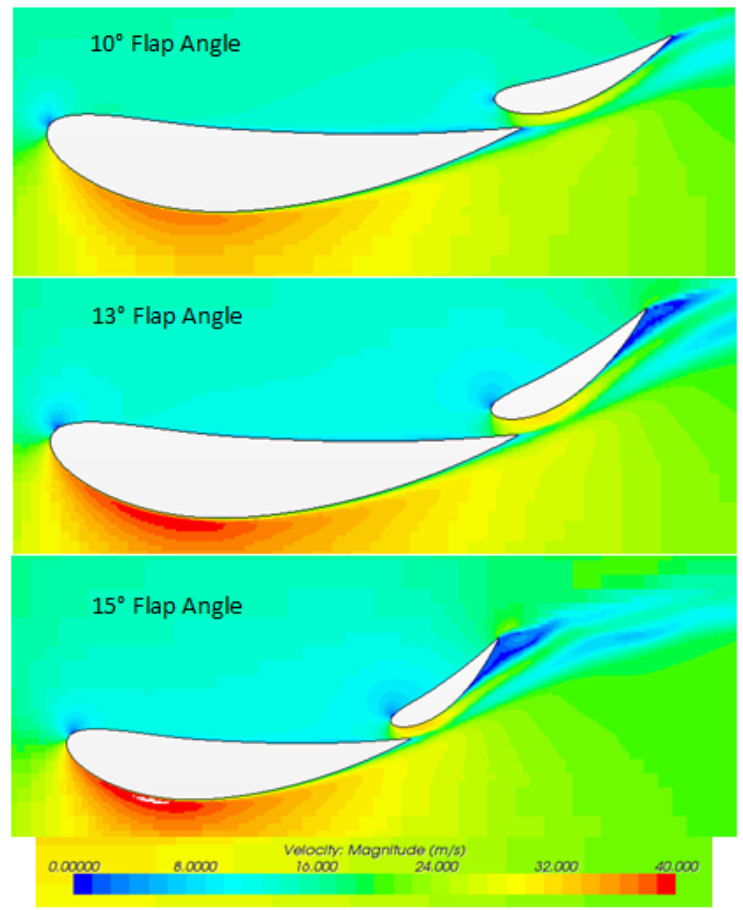

Figure 14. Velocity Magnitude showing at various Angle of Attack.

Contours of velocity magnitude, calculated in the CFD are plotted in figure 14, showing the effect of flap angle on the velocity field. Increasing the flap from 10 to 13 degrees there is a small increase in separation on the flap suction side but a large increase in the velocity on the suction side of the main element giving significant down force. Increasing further to 15 degrees the separation is more prominent and little change in the velocity around the main element suggesting that we are past the optimum configuration.

Many wing configurations were tested in CFD so an example set of results is shown in figure 15, in this case, to demonstrate the effect of the size of the (vertical) gap between the main element and the flap and the amount of overlap between the flap leading edge and the trailing edge of the main element. The results in figure 14 are all for a flap angle of 14 degrees. The results show that between overlaps of $1.2 \%$ and $2 \%$ of chord the peak lift values are obtained at a gap size of $1.6 \%$ whereas at $2.6 \%$ chord overlap there is reduced lift. The lift sensitivity to gap size is also reduced at $1.2 \%$ overlap. McBeath [8] recommends a gap size of $2 \%$.

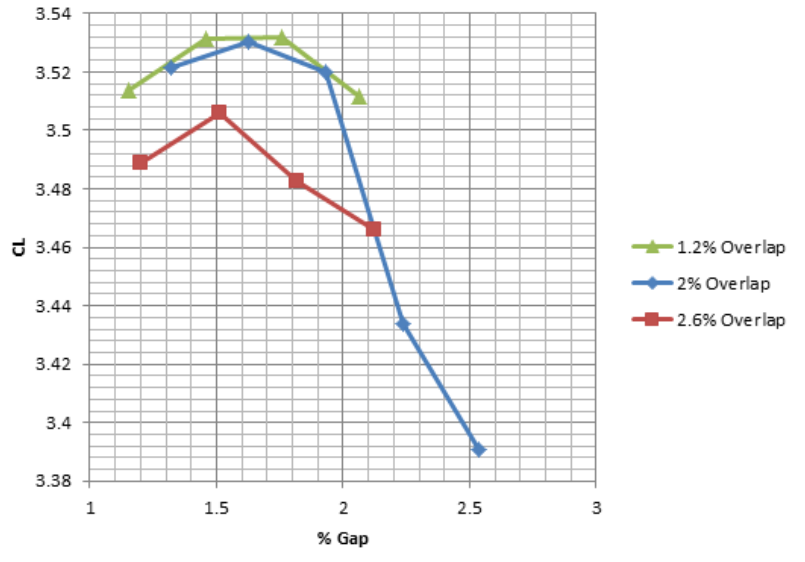

Figure 15. Gap Size and Overlap Sensitivity Study.

The problem with specifying very small slot gap sizes is the possibility of the gap closing due to deflections of either the main element or flap (span is $1.2 \mathrm{~m}$ at full scale) either under their own weight or due to the aerodynamic down-force. Because of this, a gap size of $2 \%$ will be specified, combined with an overlap of $1.5 \%$.

\section{Wing testing}

The front and rear wings were first tested individually on the wind tunnel model to evaluate the performance compared to that generated in the CFD preparatory work. Finally the complete package was tested and an optimum chosen based on the initial targets described in table 3 . The configuration of the model with wings is shown in figure 16.

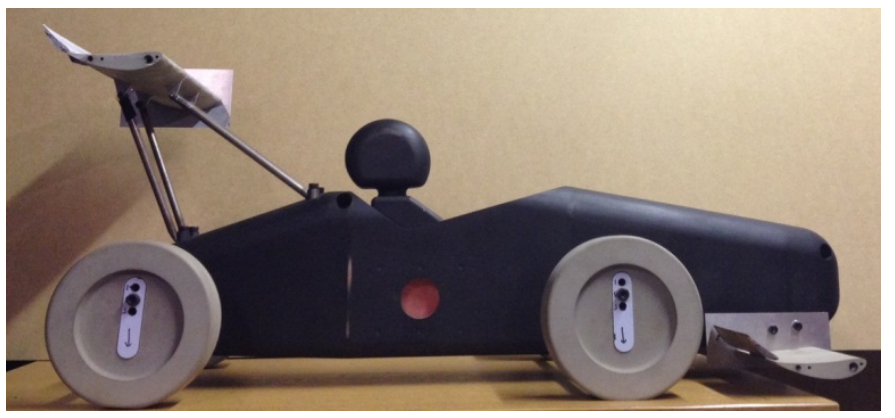

Figure 16. Wind tunnel model with wings. (Endplates removed for clarity.)

The rear wing was tested in three positions, high, medium and low, with three flap angles, 10,12 and 14 degrees and the delta lift and drag determined by subtracting the values of the baseline vehicle. The results are presented in figure 17 in the form of the ratio of the experimentally measured result to the result predicted from CFD.

For the rear wing the predicted levels of down force are closely matched by the measured results suggesting that using planes of input velocity data and interpolating to calculate total force is reasonable in this case. The drag is less well predicted, particularly at high flap angles where the separation is more important and when the wing position is closer to the body so 
that the interaction with the flow from the driver's helmet is stronger.
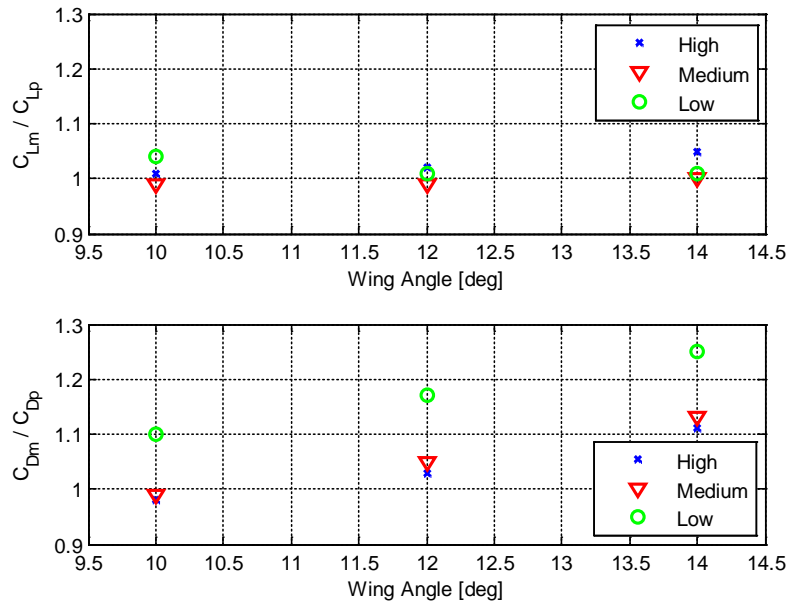

Figure 17. Rear wing performance - Ratio of measured $(m)$ to predicted ( $p$ ) lift and drag.

The longitudinal position of the front wing on the vehicle is limited by the regulations, because of crash requirements, so a single position was tested. At this location only two flap angles were possible because of the pitching moment capacity of the balance, but the results are presented in table 5 . As the predictions were performed for a wing in free air it was expected that the measured down-force would be considerably larger than predicted and this is borne out in the results. The average ratio for down-force is 1.7 and this accords well with Mokhtar [9] who's results suggest that a factor of between 1.55 and 1.75 is likely for the ground proximity used in the tests here.

Table 5 Front wing lift and drag as a ratio of predicted.

\begin{tabular}{|l|l|l|}
\hline $\begin{array}{l}\text { Flap angle } \\
\text { (degrees) }\end{array}$ & $\begin{array}{l}\text { Ratio of Measured } \\
\text { down force to predicted }\end{array}$ & $\begin{array}{l}\text { Ratio of measured } \\
\text { drag to predicted. }\end{array}$ \\
\hline 10 & 1.77 & 0.32 \\
\hline 12 & 1.62 & 0.42 \\
\hline
\end{tabular}

The measured drag is considerably less than that predicted for free stream. This is expected and attributed to a combination of effects from ground proximity and the location of the front wing close to the body and to the front wheels. However because the predicted drag is an overestimate it produces a conservative estimate of the advantages in using the aerodynamic package when used in the lap simulations.

\section{Aerodynamic Mapping}

To ensure maximum adjustability of aerodynamic balance, the highest and most rearward position of the rear wing was selected. Using the available wind tunnel data the dynamic analysis suggests that in this position the proportion of lift on the front axle can be varied between 45 and 60\%. For this configuration a full aerodynamic map was produced for the complete package. The map included two main parameter sweeps. In the first case the ride height was fixed to represent Page 8 of 10 static vehicle setup and front and rear flap angles varied. Then with the flap angles set to create a $50 \%$ aerodynamic balance, the front and rear ride heights were varied to create a ride height map.

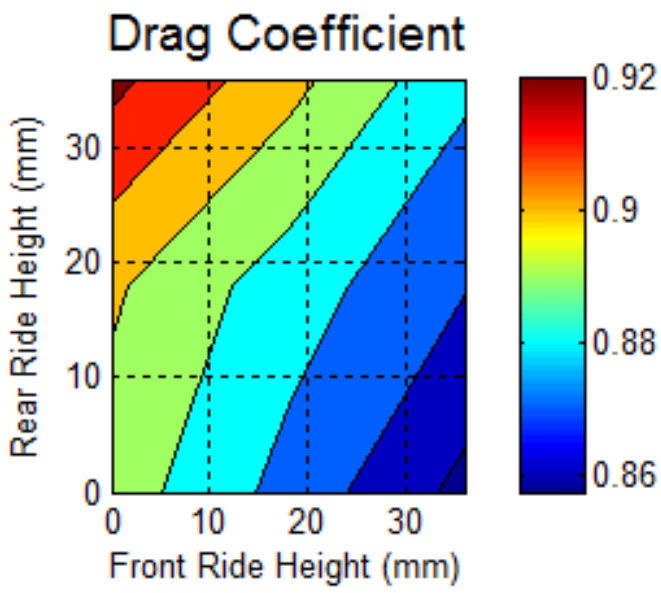

a)

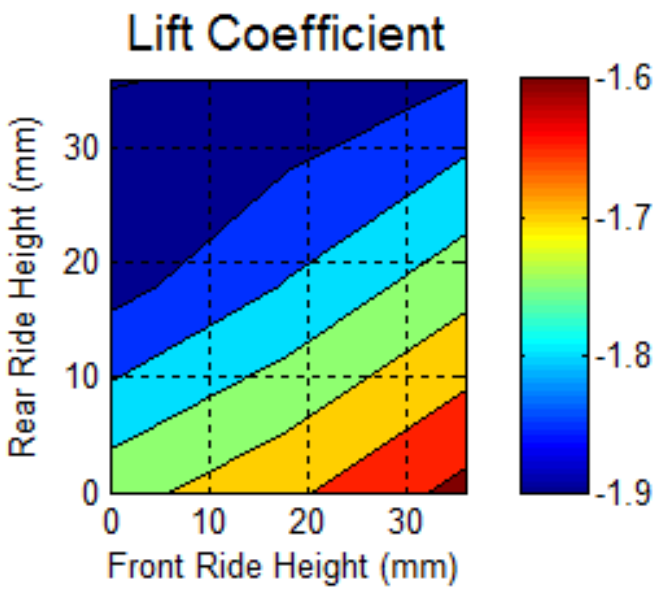

b)

\section{Pitch Moment Coefficient}

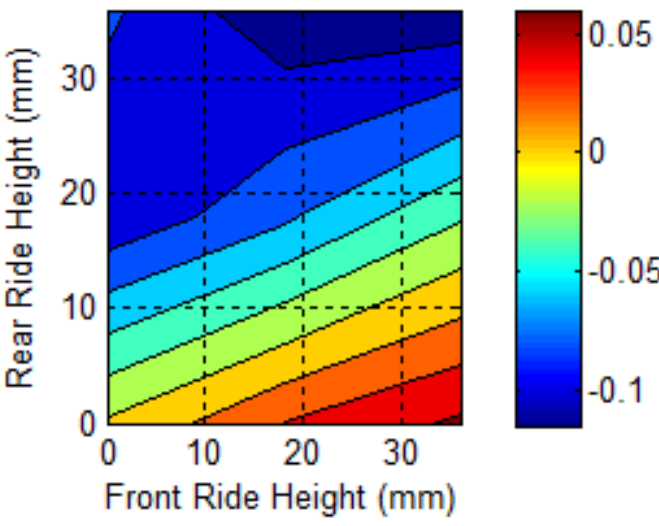

C)

Figure 18. a) Drag, b) Lift and c) Pitch Moment Coefficient Aerodynamic Map with Wings ( $\left.0^{\circ} \mathrm{Yaw}\right)$. 
The full data set can then be employed in the lap-time and dynamic handling simulations. An example data set for varying ride height is shown in figure $18 a, b, c$ showing the variation of lift, drag and pitching moment for the vehicle at zero yaw angle. Similar data sets were collected over a small range of yaw angles.

\section{Conclusion}

To conclude the work the final aerodynamic package was tested in the lap simulation tool to identify the potential gain in points for the Formula Student car, these are summarized in table 6 . As points are awarded as a proportion of the winning performance in each event, the calculation uses historical data to calculate the points in the table. In a typical event the addition of the wings would improve the position of a competitive car by about three places.

Table 6 Comparison of points with and without aerodynamic package.

\begin{tabular}{|c|c|c|c|c|c|c|}
\hline & Acceleration & Skid Pad & Autocross & Endurance & Efficiency & Total \\
\hline w/0 Aero & 70.71 & 38.14 & 113.27 & 235.56 & 69.69 & $\mathbf{5 2 7 . 3 6}$ \\
\hline with Aero & 70.94 & 41.89 & 124.78 & 255.75 & 66.53 & $\mathbf{5 5 9 . 8 8}$ \\
\hline Points Gain & $\mathbf{0 . 2 3}$ & $\mathbf{3 . 7 5}$ & $\mathbf{1 1 . 5 1}$ & $\mathbf{2 0 . 1 9}$ & $\mathbf{- 3 . 1 6}$ & $\mathbf{3 2 . 5 2}$ \\
\hline
\end{tabular}

- The simulation demonstrates an advantage for the vehicle with this simple aerodynamic package in all events apart from the fuel economy test.

- $\quad$ The broad method demonstrated in this paper is one that can be employed by any team to develop and thoroughly analyze an aerodynamic package appropriate to the resources available to the team.

- $\quad$ The use of relatively simple 2D CFD of the proposed wing sections provides useful data to guide the development of the package.

- A purpose built lap simulation and dynamics tool allows the evaluation of the package.

\section{References}

1. Wordley, S., Pettigrew, J. and Saunders,J., "Aerodynamics for Formula SAE: On-Track Performance Evaluation”, SAE International 2007-01-0897.

2. Wordley, S. and Saunders,J., "Aerodynamics for Formula SAE: A Numerical, Wind Tunnel and On-Track Study”, SAE International 2006-01-0808.

3. Rehnberg, S. et Al., "Race Car Aerodynamics - The Design Process of an Aerodynamics Package for the 2012 Chalmers Formula SAE Car”, SAE International 201301-0797.

4. Johl, G., Passmore, M., Render, P., “Design Methodology and Performance of an Indraft Wind Tunnel”, The Aeronautical Journal, September 2004 Paper No. 2881.

5. Newnham, P., "Edge Radius Optimisation” Loughborough University PhD Thesis, 2009.

6. Milliken, W. and Milliken, D., "Race Car Vehicle Dynamics”, Society of Automotive Engineers, Inc., Warrendale, PA, ISBN 978-1-56091-526-3, 1994.
7. Doddegowda, P. et Al., "Use of Computational Fluid Dynamics for the Design of Formula SAE Race Car Aerodynamics”, SAE International 2006-01-0807.

8. McBeath, S., "Competition Car Aerodynamics”, Haynes Publishing, Sparkford, ISBN 184425230 2, 2006.

9. Mokhtar, Wael A., “Aerodynamics of High-Lift Wings with Ground Effect for Racecars”, SAE International 2008-01-0656.

\section{Contact Information}

For further information contact Dr Martin A Passmore

$\underline{\text { m.a.passmore@lboro.ac.uk }}$

+44 (0)1509227250.

\section{Acknowledgments}

The authors would like to acknowledge the excellent work of the wind tunnel technician and manager, Rob Hunter, particularly for building such a high quality model in a short time. Also many thanks to Anna Perry for supervising the wind tunnel tests and ensuring the quality of the data.

\section{Appendix One}

\section{Straight-line/Acceleration (75 Points)}

A 75m acceleration from a standstill, 2 runs per driver, 2 drivers. Fastest time of all 4 runs provides your time $\left(T_{\text {your }}\right)$

Acceleration Score $=\frac{\left(71.5 \times\left(T_{\max } / T_{\text {your }}\right)-1\right)}{\left(\left(T_{\max } / T_{\min }\right)-1\right)}+3.5$

\section{Skidpad (50 Points)}

Two laps of in each direction of a figure of eight (circle diameters approx. 15m), 2 runs per driver, 2 drivers. Fastest average time in both directions provides your time $\left(T_{\text {your }}\right)$

Skid Pad Score $=\frac{\left(47.5 \times\left(T_{\max } / T_{\text {your }}\right)^{2}-1\right)}{\left(\left(T_{\max } / T_{\min }\right)^{2}-1\right)}+2.5$ 


\section{Autocross (150 Points)}

Approximately $0.8 \mathrm{~km}$ circuit consisting of straights of no longer than $60 \mathrm{~m}$, constant radius turns of $23-45 \mathrm{~m}$ radius, hairpin turns with minimum $9 \mathrm{~m}$ outer diameter, slaloms with separation of 7.6-12.2m and miscellaneous additional chicanes and multiple corners with minimum width of $3.5 \mathrm{~m}$. 2 runs per driver, 2 drivers. Fastest time provides your time ( $\left.T_{\text {your }}\right)$.

Autocross Score $=\frac{\left(142.5 \times\left(T_{\max }^{T_{\max }} / T_{\text {your }}\right)-1\right)}{\left(\left({ }^{\max } / T_{\min }\right)-1\right)}+7.5$

\section{Endurance (300 Points)}

$22 \mathrm{~km}$ in length, $11 \mathrm{~km}$ per driver with a 3 minute change over in the middle. Total time minus the changeover gives $\left(T_{\text {your }}\right)$. Circuit consists of straights of no longer than $61 \mathrm{~m}$ (or 77 if hairpins at both ends), constant radius turns of $30-54 \mathrm{~m}$ radius, hairpin turns with minimum $9 \mathrm{~m}$ outer diameter, slaloms with separation of $9-15 \mathrm{~m}$ and miscellaneous additional chicanes and multiple corners with minimum width of $4.5 \mathrm{~m}$.

Endurance Score $=\frac{\left(250 \times\left(T_{\max } / T_{\text {your }}\right)-1\right)}{\left(\left(T_{\max } / T_{\min }\right)-1\right)}+50$

\section{Fuel Efficiency (100 Points)}

The fuel efficiency calculation is based on both the fuel used during the endurance event, and how quickly the endurance was completed

$$
\begin{aligned}
& \text { Efficiency Score = } \\
& 100 \times\left(\frac{\left(\text { FuelEfficiencyFactor }_{\text {min }} / \text { FuelE f ficiencyFactor }_{\text {your }}\right)-1}{\left(\text { FuelEfficiencyFactor }_{\text {min }} / \text { FuelEf ficiencyFactor }_{\text {max }}\right)-1}\right) \\
& \text { EfficiencyFactor }= \\
& 100 \times\left(\frac{T_{\text {min }} / \text { Laptotal }_{\text {tmin }}}{T_{\text {yours }_{\text {Laptotal }}}} \times \frac{\mathrm{CO}_{2_{\text {min }}} / \text { Laptotal }_{\text {CO } 2 \mathrm{~min}}}{\mathrm{CO}_{2 \text { your }} / \text { Laptotal }_{\text {yours }}}\right)
\end{aligned}
$$

Where

$T_{\text {min }}$ is the minimum time

$\mathrm{T}_{\text {max }}$ is the maximum time

$T_{\text {yours }}$ is the time of the team

$\mathrm{CO}_{2 \text { min }}$ is smallest mass of $\mathrm{CO}_{2}$ used in the event

$\mathrm{CO}_{2 y o u r}$ is the mass of $\mathrm{CO}_{2}$ used in the event by the team Laptotal ${ }_{\text {yours }}$ is the number of laps completed by the team Laptotal $_{\text {tmin }}$ is the number of laps completed by the team with the lowest $\mathrm{CO}_{2}$ mass. 